\title{
Avaliações - nacional e internacional - no Brasil e a relação com o saber de diretores escolares
}

\section{Assessments - national and international - in Brazil and the relationship with the knowledge of school directors}

https://doi.org/10.34112/2317-0972a2021V39n82p19-41

Maria Cecília Luiz ${ }^{1}$

Aline Cristina de Souza ${ }^{2}$

Viviane Wellichan ${ }^{3}$

Resumo: Partiu-se do pressuposto de que a forma como diretores de escola têm lidado com as questões de avaliações escolares, institucionais e em larga escala tem afetado diretamente o desempenho escolar dos alunos. Objetivou-se compreender por meio da Relação com o Saber (RcS) o que sabem os diretores escolares brasileiros sobre avaliação, em geral. Este estudo de caráter qualitativo e exploratório se caracterizou pelo uso de formulário online para diretores do Brasil, aplicado em abril e maio de 2020. Concluiu-se que a RcS está relacionada com um saber advindo mais do que vem de fora (conhecimentos) do que de dentro (escolhas próprias), com pouca perspectiva de autonomia intelectual e prática. Fruto de uma pedagogia tecnicista, o diretor escolar que recebe pouca formação inicial para sua função, com grande rotatividade em sua carreira profissional, estabelece as RcS ordenadas pelas secretarias de educação, muitas vezes, sem compreensão da sua escola, da sua situação e do desempenho de seus alunos. É um diretor que possui RcS conforme seu tempo, suas obrigações imediatas, sua condição precária de ser educador no Brasil.

Palavras-chave: Diretores escolares; Relação com o Saber (RcS); avaliação.

1. Universidade Federal de São Carlos - UFSCar, São Carlos, Brasil.

2. Universidade Federal de São Carlos - UFSCar, São Carlos, Brasil

3. Universidade Federal de São Carlos - UFSCar, São Carlos, Brasil 
ABSTRACT: It was assumed that the way school principals have dealt with school, institutional and large-scale assessment issues has directly affected the students' school performance. The objective was to understand through the Relationship with Knowledge (RcS) what Brazilian school principals know about evaluation, in general. This qualitative, exploratory study was characterized by the use of an online form for directors in Brazil, applied in April and May 2020. It was concluded that SCR is related to knowledge that comes from outside (knowledge) than from within (its choices), with little perspective of intellectual and practical autonomy. The result of a technical pedagogy, the school principal who receives little initial training for his/her function, with great turnover in his professional career, establishes the RcS ordered by the departments of education, often without understanding his school, of his situation, in short of the performance of his students. He is a director who has RcS according to his time, his immediate obligations, his precarious condition of being an educator in Brazil. KEYWORDS: School directors; Relationship with Knowledge (RcS); assessment.

\section{INTRODUÇÃo}

Em função da pandemia do Sars-Covid 19, com a necessidade de efetivar o ensino remoto, profissionais da educação vivenciam um novo cenário pedagógico, de incertezas e de grandes desafios em tempos de isolamento social. A jornada desses educadores está repleta de indagações sobre inovações tecnológicas: como ensinar para estudantes com tantas informações disponíveis? O planeta está presenciando momentos de rápidas mudanças, em que todos correm atrás de informes, comunicações, notícias de todo o tipo, o tempo todo. No caso brasileiro, somam-se todos esses obstáculos ao fato de estarmos vivendo um momento de dualidade política, com um governo federal que não obtém aprovação da maioria dos brasileiros, o que resulta em mais empecilhos e morosidade nas decisões importantes para a educação, falta de planejamento e estrutura governamental.

Com o propósito de refletir sobre essas questões tendo como alvo principal a atividade fim da escola, ou seja, o êxito dos estudantes no processo de ensino e aprendizagem, este artigo tem como objetivo compreender, a partir da Relação com o Saber $(\mathrm{RcS})^{4}$, o que sabem os diretores escolares brasileiros sobre avaliação nacional e internacional, em geral. Parte-se do pressuposto de que a maneira como

4. Utiliza-se neste artigo a sigla $\mathrm{RcS}$ quando se trata da teoria da Relação com o Saber. 
os diretores de escola têm lidado com as questões de avaliações escolares, institucionais e em larga escala afeta diretamente o desempenho escolar dos alunos.

Dessa forma, o texto que se segue está dividido em três partes. A primeira seção apresenta o modo como o Brasil tem verificado o desempenho escolar por meio de avaliações nacionais e internacionais. A segunda parte aborda aspectos teóricos decorrentes da teoria da RcS, proposta pelos professores e pesquisadores Bernard Charlot, Jean-Yves Rochex e Élisabeth Baltier. E, por fim, o terceiro item evidencia os saberes de diretores sobre as avaliações nacionais e internacionais, a partir de uma análise feita com base nas respostas de gestores escolares do Brasil, resultado de uma investigação realizada pelo Grupo de Estudos (GEPESC), denominada Programa de Mentoria de Diretores, em abril e maio de 2020.

Esclarece-se que o Programa de Mentoria de Diretores Escolares, uma pesquisa que está em andamento, é fruto da parceria entre a Coordenação Geral de Formação de Gestores e Técnicos da Educação Básica da Secretaria de Educação Básica do Ministério da Educação (CGFORG/DICAP/SEB/MEC) e Grupo de Estudos e Pesquisa em Educação, Subjetividade e Cultura (GEPESC). Esse Programa busca desenvolver uma atividade-meio para a finalidade da escola, que é promover espaços sistematizados para aqueles que exercem função ou cargo na direção escolar, visando o fortalecimento da comunicação, o compartilhamento de experiências e reflexões sobre conhecimentos e práticas cotidianas.

\section{Avaliação E DeSEMPenHo ESCOLAR}

Por meio da educação se pode observar o processo de desenvolvimento de uma determinada nação; por isso, tem sido tão recorrente a procura pelos índices de avaliações externas em vários países do mundo. Neste texto, ratifica-se uma análise mais específica sobre a educação no Brasil, um país que faz parte da América do Sul, que é composta por 13 países, incluindo também: Argentina, Bolívia, Chile, Colômbia, Equador, Guiana, Guiana Francesa, Paraguai, Peru, Suriname, Uruguai e Venezuela. Uma América que possui área de aproximadamente $8.515 .767,049 \mathrm{~km}^{2}$, com cerca de 422,5 milhões de pessoas.

Essa mesma América Latina, que traz notórias diferenças econômico-sociais, políticas e educacionais, e que retrata a singularidade de cada um dos treze países que a compõem, bem como de seus sistemas de ensino, participa - como as demais nações do mundo - da avaliação externa denominada Programa Internacional de 
Avaliação de Estudantes (PISA), em que se apresentam indicadores referentes a matemática, leitura e ciências; por ela, também é possível verificar a classificação atribuída ao cenário educacional mundial.

Infelizmente, não cabe neste espaço limitado conjecturar sobre as exclusões e as diversidades dos países e suas populações na América do Sul, o que seria pertinente em tempos atuais, mas a intenção aqui é destacar dois de seus países: Brasil e Chile. Cabe neste contexto, antes de refletir a respeito de avaliações brasileiras, evidenciar a educação no Chile, uma nação com propostas educacionais que lhe renderam destaque mundial desde 2018, com três indicadores de sucesso avaliados pelo PISA: 452 para leitura; 417 para matemática e 444 para ciências. Esse bom resultado no PISA o colocou na frente de países vizinhos, como Uruguai, Colômbia, Argentina e Brasil (OECD, 2018).

A intenção não é comparar resultados, mas, avaliados mais de perto os índices da educação chilena, notam-se inúmeros investimentos e reformas educacionais - um rumo negativo a partir da ditadura de Pinochet -, com uma reestruturação educacional tanto na formação inicial (na educação básica e no ensino superior) como na continuada, com programas de mentoria de docentes e gestores, guias de orientações pedagógicas etc.

O Brasil, da mesma forma, passou por um período difícil de ditadura militar, aprovou e reestruturou muitas políticas públicas de caráter educacional, como, por exemplo, a Constituição Federal de 1988, que possibilitou a universalização do ensino, ou a Lei de Diretrizes e Bases da Educação (LDB), no 9.394 de 1996, que modificou a educação básica do país (alunos de Educação Infantil, Ensino Fundamental - Anos Iniciais e Finais - e Ensino Médio, abrangendo de 4 a 17 anos de idade), com perspectiva de gestão democrática.

Entretanto, a reorganização do sistema de ensino brasileiro não foi suficiente em termos de investimento, como no Chile, ou em alguns poucos países da América do Sul; além da falta de recursos financeiros, instituiu-se políticas de avaliação externa com enfoque no ranqueamento das escolas, com bonificação aos docentes conforme resultados de ensino e de aprendizagem etc., o que não ajudou muito, pois as avaliações externas de estudantes brasileiros na educação básica têm revelado índices de pouco sucesso frente ao cenário mundial da educação.

Por conta dessas circunstâncias, as avaliações escolares, institucionais e em larga escala se tornaram parte da trajetória escolar de alunos da educação básica das escolas e das redes públicas de ensino - como mecanismos de acompanhamento do processo 
de ensino e aprendizagem -, sendo que essas avaliações externas são aferidas pelo Índice de Desenvolvimento da Educação Básica (IDEB) desde 2007, no Brasil.

O IDEB foi criado pelo Ministério da Educação (MEC) e consiste em um indicador de qualidade educacional, que combina informações de desempenho em exames padronizados. A avaliação em larga escala, a partir da década de 1990 - por meio do IDEB - se desdobra em Prova Brasil e/ou Sistema de Avaliação da Educação Básica (SAEB), aplicadas no final das etapas de ensino (ciclos de aprendizagens).

O SAEB e a Prova Brasil são avaliações externas que têm como escopo mensurar habilidades cognitivas dos estudantes da educação básica sobre conteúdos pertinentes a Língua Portuguesa e Matemática, com o objetivo de proporcionar indicativos sobre a qualidade de ensino nas escolas (CHIRINÉA; BRANDÃO, 2015).

Segundo Nardi, Schneider e Rios (2014), a expressividade do IDEB é associada à verificação de quanto as escolas avançam nas metas educacionais. Sendo assim,

Razões como sua capacidade de deteç̧ão de escolas e redes nas quais seus estudantes apresentem baixa performance e de monitoramento da evolução temporal do desempenho dessas escolas ou redes justificariam, segundo seus idealizadores, a relevância da adoção desse índice oficial (NARDI; SCHNEIDER; RIOS, 2014, p. 360)

Para os autores, o IDEB é o referencial de qualidade da educação com maior força nas políticas públicas educacionais brasileiras. Ele traz pontos de vista diferenciados: um primeiro, diz respeito à natureza quantitativa de aprovação e desempenho de estudantes, ancorados em um sistema de avaliação externo à escola. Essa perspectiva desafia os sistemas de ensino municipais, estaduais e particulares a acompanhar as políticas de planejamento educacional a partir do IDEB, com metas traçadas pelo MEC (NARDI, SCHNEIDER e RIOS, 2014); e, o segundo, consiste em acolher as necessidades da comunidade escolar específicas de cada lugar, com um país de dimensões territoriais gigantescas que abarca várias diversidades locais.

O IDEB traçou uma meta final para alunos dos anos iniciais do Ensino Fundamental ( $1^{\circ}$ a $5^{\circ}$ anos - com 6 a 10 anos de idade) de valor seis, um alcance nacional estimado para o ano de 2021, com divulgação dos resultados em 2022. Para discentes dos anos finais do Ensino Fundamental ( $6^{\circ}$ a $9^{\circ}$ anos - com 11 a 14 anos de idade), estima-se que essa mesma meta (seis) seja alcançada em 2025; e, para o Ensino Médio (com 15 a 17 anos de idade), a expectativa é que seja obtida em 2028. 
Além de propositor de políticas públicas, o IDEB tem sido indutor de ações das escolas para efetivação da qualidade; mesmo sendo um indicador de resultado e não de qualidade, tais resultados possibilitam mobilizações e mudanças de ações para a melhoria da qualidade da educação (CHIRINÉA; BRANDÃO, 2015).

A avaliação da educação básica é organizada e realizada pelo INEP a cada dois anos e aplicada aos discentes dos últimos anos de cada etapa da educação básica, sendo que o INEP recebe assessoria de empresa especializada para a constituição de base de dados e produção de escolas de proficiência; essa contratação é realizada por meio de licitação internacional (SILVA, 2010). Segundo Silva (2010), o SAEB (Aneb) acontece segundo abrangência amostral, conforme tratamentos estatísticos, sendo escolhidos alunos da última etapa do Ensino Fundamental dos anos iniciais e finais de sistemas públicos e privados de áreas urbanas e rurais, e do terceiro ano do Ensino Médio de sistemas públicos e privados de áreas urbanas, cujos resultados representam o desempenho escolar de regiões e/ou unidades da federação brasileira.

Os indicadores traçados pelo Brasil são alcançados, desde 1990, por meio do Sistema de Avaliação da Educação Básica (SAEB), que passou por várias estruturações até chegar ao seu formato atual. Esse sistema se constitui em um conjunto de avaliações externas que permite ao INEP realizar um diagnóstico da educação básica e dos fatores que interferem no desempenho dos estudantes. Segundo Silva (2010), o SAEB é composto por duas provas complementares: Avaliação Nacional da Educação Básica (ANEB) e Prova Brasil, sendo a última composta pela Avaliação Nacional de Rendimento Escolar (Anresc); o Ensino Médio (última etapa da educação básica) é avaliado pelo Exame Nacional do Ensino Médio (ENEM).

A Prova Brasil fornece médias de desempenho escolar desde 2005, com alcance em áreas urbana e rural de escolas públicas, para estudantes da última etapa dos anos iniciais e finais do Ensino Fundamental ( $5^{\circ}$ anos e $9^{\circ}$ anos). A metodologia das duas avalições (anos iniciais e finais do Ensino Fundamental) sempre foi a mesma, por isso elas passam a ser operacionalizadas em conjunto a partir de 2007.

Como já foi dito, além das avaliações realizadas em âmbito nacional, os estudantes brasileiros participam do Programa Internacional de Avaliação de Estudantes (PISA), tradução de Programme for International Student Assessment, desde o início da primeira edição, em 200o. O INEP é responsável pelo planejamento e a operacionalização dessa avaliação no país, além de representá-lo na Organização para a Cooperação e Desenvolvimento Econômico (OCDE). A cada três anos é realizado um estudo comparativo internacional por meio do PISA, por isso suas informações 
são importantes e permitem aos países avaliarem conhecimentos e habilidades de seus discentes em âmbito mundial (BRASIL, 2020).

Por serem indicativos de como se processa o ensino e a aprendizagem em um país, as avaliações externas possuem certa relevância. No presente estudo, tem-se a certeza de que a função do diretor de escola é extremamente importante na condução desse processo. Por isso, foi proposto para este artigo compreender as $\mathrm{RcS}$ desses diretores frente ao processo de avaliação (índices e metas) considerando-se a seguinte questão problematizadora: como diretores têm enfrentado o cotidiano escolar, superando desafios para alcançar metas do IDEB, com melhorias no processo ensino e aprendizagem?

\section{RELAÇÃO COM O SABER - RCS}

Abarcar perspectivas teóricas relacionadas à Relação com o Saber $(\mathrm{RcS})$, frente aos saberes escolares e ao aprendizado, tem possibilitado entender melhor o que acontece nas escolas públicas da educação básica brasileira, mais especificamente, com diretores, docentes, discentes e funcionários de um modo geral. Bernard Charlot e colaboradores têm debatido questões que envolvem a $\mathrm{RcS}$ a partir de produções teóricas que abordam o que os agentes da escola sabem, ou dizem que sabem, sobre educação; por isso debater questões antigas e novas demandas educacionais se torna tão necessário.

Charlot (2013), baseado em teorias como a de Monteil (1985) e de Schlanger (1978), estabeleceu diferenças significativas entre informação, saber e conhecimento. Conforme suas palavras: "o conhecimento é o resultado de uma experiência pessoal, ligada à atividade de um sujeito provido de qualidades afetivo-cognitivas; como tal é intransmissível, está sob a primazia da subjetividade" (CHARLOT, 2013, p. 61). Portanto, a informação e o saber estão no campo da objetividade, quer dizer, no mundo, fora do sujeito, e podem ser armazenados como um banco de dados que pode ser transmitido de forma virtual ou impressa. O saber, no entanto, difere da informação, porque indica uma apropriação pelo sujeito e, portanto, aproxima-se da noção de conhecimento. $\mathrm{O}$ docente que acredita que está ensinando no formato antigo de transmissão de informações corre o risco de ser caçoado pelos seus discentes, pois estes conseguem encontrar várias informações atualizadas sobre variados temas apenas acessando seus celulares, via internet.

Charlot indica que o que importa é atuar como professor do saber, e isso significa questionar qual é o sentido que pode ser atribuído às informações que estão 
disponíveis. O que difere a informação do saber é a produção de sentido que o sujeito estabelece sobre a informação, isto é, como ela chega e se lhe permite, ou não, produzir sentido ou sentidos. O sujeito produz saber, tornando-se a própria relação com o saber.

Ao analisar a RcS dos diretores de escolas brasileiros, buscou-se verificar os aspectos que transpunham um conjunto de sentidos, assim como informações rotineiras institucionalizadas pelo sistema de ensino em que estão inseridos, como regras e valores instituídos etc. Essa produção de sentido permite estabelecer suas representações e formas de identificação, com culminância na forma como se é no interior desse conjunto das relações:

um "conteúdo de pensamento", uma atividade, uma relação interpessoal, um lugar, uma pessoa, uma situação, uma ocasião, uma obrigação etc., relacionados de alguma forma ao aprender e ao saber - consequentemente, é também relação com a linguagem, relação com o tempo, relação com a atividade no mundo e sobre o mundo, relação com os outros e relação consigo mesmo, como mais ou menos capaz de aprender tal coisa, em tal situação (CHARLOT, 2001, p. 45).

Nesse aspecto, "a relação com o saber é buscar compreender como o sujeito apreende o mundo e, com isso, como se constrói e transforma a si próprio" (CHARLOT, 2005, p. 41). Assim, quando um diretor expõe suas representações sobre a escola e sua corporeidade (alunos, ensino, professores, familiares, legislações etc.), passa pela produção das representações, pelo processo que estabelece o que ele é, com possibilidades de se refletir sobre o que virá a ser, isto é, o sujeito se constitui diretor no processo de RcS. Se ao diretor for oferecida a oportunidade de novas representações, novos saberes, com certeza poderá ter nova perspectiva sobre si mesmo e sobre a escola em que atua.

A proposta de analisar a $\mathrm{RcS}$ de diretores brasileiros sobre avaliações não deve ser generalizada, visto que esta investigação buscou pistas para encontrar referências sobre experiências vividas de quem está atuando e sobre saberes que estão sendo produzidos. Parte-se do pressuposto de que esses educadores estão o tempo todo se inspirando e produzindo novos saberes no trabalho de gestão escolar, por isso estes não podem ser utilizados como único para todos os gestores escolares.

$\mathrm{O}$ item a seguir trata da leitura dessas respostas de diretores e sua estrutura foi dividida em três dimensões, de acordo com as figuras do aprender e/ou como aprendem o que dizem saber. Essas dimensões ou formas do saber, apresentadas a 
seguir, buscaram captar os processos de como os diretores produzem saberes como profissionais da educação com foco nas avaliações.

\section{Delineamento Metodológico}

Com caráter qualitativo, esta pesquisa exploratória se caracterizou pelo uso de formulário online, não estruturado, de autopreenchimento, disponível em um link enviado através de convite eletrônico à totalidade de diretores escolares do Brasil que possuem endereços de e-mail cadastrados na base do PDDE interativo, aplicado em abril e maio de 2020. Para analisar a RcS de diretores escolares a respeito das avaliações externas no Brasil foram utilizados os resultados da investigação realizada no Programa de Mentoria de Diretores desenvolvida pelo GEPESC da Universidade Federal de São Carlos (UFSCar). O formulário foi elaborado no Lime Survey, o qual possuía uma caracterização inicial do participante, e, posteriormente, duas perguntas a serem respondidas:

a. Quais problemas, e seus contextos, que você, como diretor (a), enfrentou e conseguiu dar uma boa resposta e/ou realizar uma ação com sucesso, atendendo às expectativas da maioria dos sujeitos da escola?

b. Como diretor de escola, o que você indica ser um desafio ou julga ser importante relatar quando se trata da busca pela melhoria da qualidade de ensino?

Esse formulário apresentou perguntas de respostas livres, espontâneas e sem qualquer tipo de estímulo. $O$ sistema de coleta de respostas foi planejado de forma a não permitir que o mesmo entrevistado respondesse mais de uma vez à pesquisa, assegurando a unicidade das respostas, considerando a representatividade do universo de participantes.

Depois de um período de um mês, várias respostas foram computadas no sistema, mas para garantir a proporcionalidade referente ao número de escolas e alunos de cada uma das cinco regiões brasileiras - norte, nordeste, centro-oeste, sudeste e sul -, criou-se uma amostra quantitativa, permitindo uma abrangência nacional de gestores de escolas públicas e/ou privadas, a nível federal, estadual e municipal. Essa amostra foi constituída, inicialmente, de 1200 respostas, mas foram descartadas as respostas de 
coordenadores, vice-diretores e outros, além de serem rejeitadas as respostas incompletas, o que acabou resultando em um total de 983 respostas validadas para esta pesquisa.

O tratamento dos dados foi feito com auxílio da ferramenta computacional denominada Iramuteq ${ }^{5}$. Essa ferramenta correlaciona as ocorrências de palavras nas respostas, permitindo a visualização e representação de massas de dados robustas. Os descritores utilizados foram: avaliação, aprendizagem, avaliação institucional, provas externas, IDEB, SAEB e ENEM. Como se vê na tabela 1:

\begin{tabular}{|c|c|c|c|}
\hline Descritores & Respostas da questão 1 & Respostas da questão 2 & Total \\
\hline Avaliação & 15 & 13 & 28 \\
\hline Aprendizagem & 151 & 188 & 339 \\
\hline Avaliação institucional & 1 & - & 1 \\
\hline Provas externas & 2 & - & 2 \\
\hline IDEB & 24 & 4 & 28 \\
\hline SAEB & 5 & - & 5 \\
\hline ENEM & 6 & 3 & 9 \\
\hline
\end{tabular}

Quadro 1. Descritores das respostas dos diretores escolares - Fonte: Elaboração das autoras.

Como se percebe pelos descritores, o que mais se destacou nas respostas dos diretores foi sem dúvida a palavra "aprendizagem" (apareceu 339 vezes); em seguida, houve um empate entre as palavras "avaliação" e "IDEB" (apareceu 28 vezes), o que indica uma primeira figura do saber desses educadores.

\section{ANÁLISE DOS DADOS}

$\mathrm{O}$ que os diretores de escola dizem saber sobre avaliação? E avaliações internas e externas? Este é o objetivo deste artigo, compreender o balanço do saber (CHARLOT, 2009) ou, ao menos, um balanço do que os diretores dizem saber sobre avaliação, por meio de um formulário online. O foco está em compreender

5. Iramuteq é a sigla para Interface de R pour les Analyses Multidimensionnelles de Textes et de Questionnaires.É um software gratuito e com fonte aberta, desenvolvido por Pierre Ratinaud (Lahlou, 2012; Ratinaud; Marchand, 2012) e licenciado por GNU GPL (v2), que permite fazer análises estatísticas sobre corpus textuais e sobre tabelas indivíduos/palavras. Ele ancora-se no software R [www.r-project.org] e na linguagem Python [www. python.org] (CAMARGO, B.V.; JUSTO, A. M., 2013). 
seus saberes quanto aos diferentes tipos de avaliação (nacional e internacional), visto que ao dar voz aos educadores - com intenção de saber seus posicionamentos sobre avaliação, desempenho escolar, processo de ensino e de aprendizagem -, buscou-se refletir sobre problemas relacionados à qualidade da educação.

Compreender como os diretores se relacionam com o saber, ou pelos menos o que dizem saber sobre avaliação em geral, a princípio significou entrar em uma perspectiva relacional, pois para Charlot (2013), o "saber" ou "aprender" inclui três dimensões: aprender apropriando-se (saber objeto); aprender dominando uma atividade; e, aprender a ser (dispõe-se com relação aos sentimentos e relacionamentos). Assim, o autor inicia as análises, citando essas três relações epistêmicas sobre como se aprende. Segundo Charlot (2013),

Aprender pode ser apropriar-se de um objeto virtual (o 'saber'), encarnado em objetos empíricos (...). Aprender também pode ser dominar uma atividade, ou capacitar-se a utilizar um objeto de forma pertinente (...). Aprender pode ser também aprender a ser solidário, desconfiado, responsável, paciente...; a mentir, a brigar, a ajudar os outros...; em suma, a 'entender as pessoas', 'conhecer a vida', saber quem se é (CHARLOT, 2013, p. 68-70 - grifos nossos).

Essas três dimensões, baseadas em Charlot (2013), foram utilizadas para analisar as figuras do saber nas respostas dos diretores sobre avaliações externas e/ou avaliações em geral, como se vê a seguir.

\section{DIMENSÃO DO APRENDER APROPRIANDO-SE}

Na dimensão do aprender apropriando-se (saber objeto), observou-se na resposta do diretor "A" da Região Sul que a avaliação só estabelece um significado quando se trata de um processo participativo. Conforme suas palavras:

A avaliação, ao meu entender, é um dos aspectos mais complexos da educação. Promover um processo de avaliação participativo, diagnóstico e justo, que favoreça a aprendizagem e possibilite aos envolvidos o entendimento desse processo e de suas ferramentas é o maior desafio que nossa gestão vem enfrentando. Acreditamos que temos conseguido trabalhar de forma a alcançar bons resultados. Revisar e adequar os conteúdos de cada ano ciclo à base curricular nacional, organizando o cotidiano 
com princípios claros de aprendizagem e promovendo a corresponsabilidade de todos os envolvidos nesse processo. Além disso, a parametrização da avaliação que promovemos permitiu melhor entendimento dos alunos e seus familiares, e, consequentemente, uma qualificação na aprendizagem, à medida que perceberam a necessidade de envolvimento e participação efetiva (Diretor A; escola municipal; 3 anos de direção escolar; estado do Rio Grande do Sul - Região Sul - grifos nossos).

Vê-se que o diretor "A" se preocupou em descrever a avaliação como um saber objetivo, cujos conhecimentos, como revisar e adequar conteúdos de ciclos conforme a base curricular nacional, organizar princípios claros de aprendizagem, promover corresponsabilidade de todos os envolvidos no processo etc., resultam em algo positivo.

O diretor "B" da Região Norte não só declarou a importância do saber-objeto com apontamentos sobre dificuldades em sua escola, como evasão escolar, falta de participação dos familiares e dificuldade de aprendizado com distorção idade/série, mas também atribuiu ao seu próprio "saber", ou o que determina ser a sua figura do "saber", como formação acadêmica, seriedade e dedicação, a resolução desses problemas. Em suas palavras:

No momento o grande problema que enfrentamos é o alto índice de evasão escolar e de retenção e infelizmente ainda não conseguimos desenvolver ações que conseguissem reduzir esses índices satisfatoriamente. Pouca participação efetiva de pais ou responsáveis na vida escolar dos alunos. Buscou-se parceria com conselho tutelar e outros, reuniões de pais e mestres realizadas bimestralmente, acompanhamento individual de frequência e rendimento escolar de cada aluno. Dificuldade de aprendizado e distorção idade/série. Para se ter uma ideia, em menos de 4 anos na gestão, estamos no nono secretário estadual de educação. Contudo, minha formação, mestre em gestão e avaliação da educação pública e meu comportamento sério e dedicado ao trabalho, validou minha liderança perante alunos e professores de modo que chegamos ao final do ano sem maiores problemas. Nesse contexto, conseguimos elevar o IDEB dos anos finais do ensino fundamental de 4,3, em 2015, para 5,2, em 2017 (Diretor “B”; escola estadual; 2 anos de direção escolar; estado do Amazonas - Região Nordeste - grifos nossos).

Este diretor (B) conferiu todo sucesso de "elevação do IDEB" nos anos finais do Ensino Fundamental a sua pessoa, aos seus saberes, julgando-se um líder 
competente perante discentes e docentes; uma situação interessante de centralidade nas suas habilidades e conhecimentos.

Outro aspecto com relação ao saber objetivo, com enfoque em conhecimentos, foi percebido pelo diretor "C" da Região Sudeste, em que a gestão de resultados é vista como estratégia para "subir notas nos indicadores externos". Sua resposta:

Gestão de resultados: desenvolvemos a cultura de trabalhar com a gestão de resultados tanto da equipe gestora para com a equipe docente, quanto entre os professores no acompanhamento das suas turmas. Com isso, as estratégias e métodos adotados pelos professores produziram mais resultados, e a escola tem subido a nota nos indicadores externos: IDESP e IDEB (Diretor C; escola estadual; 4 anos de direção escolar; estado de São Paulo - Região Sudeste - grifos nossos).

O diretor "C" é gestor de uma escola estadual do estado de São Paulo, por isso traz em sua resposta um saber sobre a perspectiva da gestão de resultados, uma política pública adotada pela Secretaria de Educação de São Paulo. O governo desse estado se perpetua há mais de 20 anos com o mesmo partido político, e por isso mantém uma figura de saber estabelecida para seus diretores. Destaca-se que os diretores do estado de São Paulo são em sua maioria concursados, isto é, prestam concurso público, realizando provas com referencial teórico e bibliografia indicados pelo próprio governo.

\section{DIMENSÃO DO APRENDER DOMINANDO UMA ATIVIDADE}

Na dimensão do aprender dominando uma atividade, apareceram respostas como a do diretor " $\mathrm{D}$ ”, também da Região Sul, pois através da sua escrita fica perceptível que as atividades ou ações promovem bons resultados à escola. Por isso, faz questão de dizer que os saberes da sua escola (seus educadores) vêm de projetos, feiras e fóruns, e indica que essas ações têm trazido melhorias para a educação. Conforme suas palavras:

No âmbito didático pedagógico: implantação do projeto da hora atividade, desde 2011; elevação dos coeficientes nas provas de avaliação externa; participação bastante positiva em competições de atletismo e paratletismo (em níveis municipal, regional, estadual); participação em projetos, feiras e fóruns realizados com entidades parceiras; projeto de ensino aprendizagem, com destaque em nível estadual no concurso 
professores do Brasil; entre outros (Diretor D; escola estadual; 6 anos de direção escolar; estado do Rio Grande do Sul - Região Sul - grifos nossos).

Entre as várias atuações elencadas, o objeto-saber é definido pelo enunciado "elevação dos coeficientes nas provas de avaliação externa”. A busca por aumentar os números (classificação) dos coeficientes (elementos) da avaliação externa chama a atenção, não por se tratar de algo errado, mas porque revela uma RcS do diretor “ $D$ ": a necessidade de domínio de atividades. Esse domínio de atividades se constitui com elementos matemáticos, quantificáveis e, na sua visão, pode ser tratado de forma simples.

Destaca-se que a avaliação (qualquer que seja) aborda diferentes graus de dificuldades, além da importância relativa que define a satisfação com o desempenho escolar do aluno, isto é, vários atributos sempre muito complexos, um saber que deve ser aprofundado. Ao considerar, como figura do saber, algo tão quantitativo, o diretor se esquece da complexidade da avaliação externa e da sua relação com outros saberes, como ensino, aprendizagem, metodologia, forma de avaliar etc.

O diretor "E" da Região Centro-Oeste também acredita em ações como, por exemplo, desenvolver e dar continuidade ao Projeto Político Pedagógico (PPP) da escola com reavaliação de pontos negativos. Os saberes dos educadores estão em reavaliar o PPP - principal documento da escola - a partir de melhorias para a educação, mas ele não cita qual seria esta fórmula mágica. Conforme suas palavras:

Criação de PPP desenvolvido ao longo dos anos e tendo continuidade com reavaliação dos pontos negativos nos anos anteriores e que abrange uma grande diversidade. (Diretor E; escola federal; 4 anos de direção escolar; Distrito Federal - Região Centro-Oeste - grifos nossos).

Nesta dimensão do aprender "dominando uma atividade", também se vê outra resposta, a do diretor " $F$ ", novamente da Região Sul, que enfatizou que ações pensadas, planejadas e executadas diminuíram os índices de reprovação e aumentaram o IDEB da escola. Conforme seus dizeres:

Ao assumir a gestão da escola, enfrentamos problemas com altos índices de reprovação, bullying, brigas, entre outros. Na questão dos altos índices de reprovação, organizamos uma planilha com os nomes, séries e idades dos alunos que vinham reprovando, destacando os anos de reprovação que se repetiam. Com estes dados, reunimos professores e funcionários da escola para fazer uma reflexão sobre as causas destes altos índices 
e pensarmos ações para enfrentar esta problemática. Conseguimos, com as ações pensadas, planejadas e executadas, diminuir os índices de reprovação e aumentar o IDEB da escola (Diretor F; escola estadual; um ano de direção escolar; estado do Rio Grande do Sul - Região Sul - grifos nossos).

Neste mesmo aspecto, o diretor "G", ao tratar do IDEB da sua escola, na Região Norte, relaciona as atividades desenvolvidas pelos educadores, como a formação continuada e as reuniões de planejamento com a coordenação pedagógica, como saberes que proporcionaram bons resultados. Nas suas palavras:

Diante de todos os problemas, realizamos algumas ações, bem como autoavaliação, reuniões, projetos, encontros, excursões, eventos culturais e esportivos, visita domiciliar, formação, parceria com os órgãos, secretarias de saúde, ação social, polícia civil, militar e rodoviária, executivo, o legislativo e o judiciário, amigos da escola, voluntários e comunidade escolar. Por conseguinte, mediante as estratégias citadas acima, obtivemos bons resultados, o que tornou o meu trabalho muito mais flexível e satisfatório (Diretor G; escola estadual; um ano de direção escolar; estado do Amazonas - Região Norte - grifos nossos).

Destaca-se que com apenas um ano de direção escolar, o diretor " $G$ " já compreende que bons resultados no IDEB implicam em realizações de várias atividades pedagógicas, sendo que, quanto mais ações, melhor. Pontua-se que não se discorda de tal descrição feita pelo diretor, mas fica a sensação de que as estratégias citadas dão conta (por elas mesmas) da obtenção de bons resultados; mas perguntamos: o que seriam essas estratégias tão poderosas? Será que existe um saber ou um conjunto de saberes que as definem?

A complexidade que envolve as avaliações externas esbarra na vontade de aprender dos alunos, questão sempre mencionada por Charlot (2013). Isso fica tão confuso para os educadores em geral que o diretor " $\mathrm{H}$ " diz, ao contrário, que o IDEB baixo acontece por falta de interesse dos profissionais da escola. Em suas palavras:

A escola tinha IDEB baixo, por falta de interesse dos profissionais da escola. Foi promovido um projeto pedagógico coeso, com participação de todos e maior acompanhamento em sala das atividades desenvolvidas (Diretor $\mathrm{H}$; escola estadual; 6 anos de direção escolar; Distrito Federal - Região Centro-Oeste - grifos nossos). 
Para o diretor "H", falar sobre avaliação (IDEB) significa ter domínio de algumas atividades, como já foi dito, por conta de políticas públicas educacionais que estabelecem um ranqueamento entre escolas; existe um saber-objeto quantitativo que o faz conferir responsabilidade total aos profissionais da educação pelo baixo IDEB da escola. É claro que existe uma parcela de corresponsabilidade de todos quando se trata de avaliar o desempenho escolar de estudantes, mas a forma como isso foi afirmado revelou certo grau de apoio aos órgãos governamentais quando estes culpabilizam os educadores pelo fracasso da educação no Brasil, algo que vários diretores repetem como figura do saber.

O diretor "I", da Região Nordeste, acredita que discorrer sobre avaliação (IDEB; SAEB) significa cobrar mais do Estado, de ações governamentais, ao contrário do diretor "H"; "I" afirma que o problema não está nas questões internas da escola, mas nas questões macro das políticas educacionais, no investimento de melhorias físicas na unidade escolar. Em suas palavras:

Melhorar o IDEB utilizando de boas práticas com o pressuposto dos indicativos e descritores da SAEB e, sabe, como melhoria do ensino e da aprendizagem. Nosso maior problema atualmente consiste na adequação física da unidade escolar, conseguimos resolver algumas etapas com muita cobrança e empenho junto ao estado (Diretor I; escola estadual; 6 anos de direção escolar; estado da Bahia Região Nordeste - grifos nossos).

Para Charlot (2013), a escola como instituição pública e seus educadores têm que atrair os alunos para aprender aquilo que se considera importante do ponto de vista dos adultos, professores e outros, mas alerta: para que o discente goste de estudar, a escola precisa desenvolver nele o gosto pela atividade intelectual, mobilizá-lo intelectualmente; esse é um desafio, pois crianças, adolescentes e jovens, geralmente, não estão acostumados, ou, às vezes, interessados nisso.

A pedagogia tradicional, com base em regras e disciplinarização de estudantes (e que faz parte do saber de vários diretores), se contradiz com outra perspectiva pedagógica, aquela baseada em desejos. Para essa pedagogia, a escola seria fundamentada no desejo do aluno, mas também no do professor e no de outros adultos que lá convivem. 
O diretor "J", da Região Nordeste, afirma conseguir redefinir o ânimo ou o desejo dos estudantes com ações compartilhadas entre profissionais de dentro e de fora da escola. Nas suas palavras:

Através de uma ação conjunta da gestão, professores, funcionários, família e os próprios alunos conseguiram despertar o ânimo de uma grande parcela dos alunos com aulas de reforço, aulas práticas, acompanhamento psicológico, parcerias com empresas e universidades para dar perspectiva de emprego e estágio para aqueles que se destacarem e permanecerem na escola (Diretor J; escola estadual; 5 anos de direção escolar; estado do Ceará - Região Nordeste - grifos nossos).

O mais interessante é que essas parcerias expõem não apenas um problema que os sujeitos identificam na escola, mas revelam as suas figuras de saber e de como eles a entendem.

\section{DIMENSÃO DO APRENDER A SER}

$\mathrm{Na}$ dimensão do aprender a ser (dispõe-se com relação aos sentimentos e relacionamentos) ocorreram respostas como a do diretor "L", da Região Sudeste, com várias perspectivas de melhoria da avaliação institucional com a participação de familiares. Nas palavras do diretor:

Não tínhamos a participação da família em nossa escola, os pais tinham uma visão assistencialista. Foram feitas reuniões escolares, buscando acolher a família em diversos momentos, fazendo com que estas participassem da rotina de nossa escola, informando quais eram os objetivos em relação aos seus filhos. Efetivamos nossa APM e conselho escolar com total participação desses pais nas tomadas de decisões. No final do ano letivo, realizamos a avaliação institucional com a participação democrática de toda equipe escolar e comunidade, onde avaliamos os pontos positivos e negativos de nossa escola, e, juntos, levantamos ações de pouco, médio e longo prazo para sanar nossas carências (Diretor L; escola municipal; 3 anos de direção escolar; estado de São Paulo - Região Sudeste - grifos nossos).

Da mesma forma, o diretor “M”, da Região Nordeste, apostou na convivência e na valorização da cultura de alunos e seus familiares. Nas palavras do diretor: 
Convivência com alunos rebeldes difíceis de lidar. A solução foi fazer amizade e conquistar a confiança, valorização da cultura, buscar dividir os momentos difíceis de convivência familiar, acolher. Presença da família na escola é um problema frequente em todos os anos. Foram implantadas algumas ações, como a melhoria da comunicação com os pais e responsáveis, o chamamento intencional a atividades e projetos envolvendo a escola, como datas comemorativas, palestras etc. (...) Índice do IDEB durante o período que estive na direção da escola municipal, no segmento dos anos iniciais, esteve acima da média projetada, devido ao trabalho de incentivo por parte da direção, acompanhamento por parte da coordenação e empenho por parte de professores e alunos; conselho escolar atuante no incentivo e oportunidades concretas de participação nas decisões e projetos da escola. (Diretor M; escola municipal; 4 anos de direção escolar; estado da Bahia - Região Nordeste - grifos nossos).

Em ambas as respostas, os diretores que optaram por envolver os alunos e seus familiares se dispuseram a ouvi-los, para decidir em conjunto. E essa figura do saber tem apresentado bons resultados, não só para os casos em que houve essa disponibilidade, mas para outras experiências educacionais relatadas em pesquisas nacionais e internacionais.

Nesse sentido, o que se viu foi um jeito de ser diretor, pois o aprender é sempre aprender a ser, segundo Charlot (2013). O saber expresso pelos diretores indicou a perspectiva de dialogar, de se comunicar com todos os envolvidos. Considerar, "falar com" e não apenas "falar para" o outro pode ser uma forma de valorizá-lo, pois "falar com" já denota falar e ouvir. O diálogo implicou em ponderar o que diz e pensa o outro, que não é diretor da escola, mas é professor, familiar/responsável, aluno etc., com intenção de sentir-se no lugar do outro e compreender sua perspectiva.

Afinal, como se aprende a dialogar com discentes, familiares, docentes etc.?

Atualmente, acredita-se que mesmo não querendo ouvir, o diretor se vê em situações em que não possui muitas escolhas, pois o escutar e opinar traz a corresponsabilidade aos sujeitos envolvidos com a escola, conforme os resultados obtidos. A ideia de um diretor administrar a escola de forma centralizada, ou gerindo-a sozinho, está entre os saberes que os diretores dizem que possuem, isto é, é algo superado. Veja-se o diretor O:

Infrequência dos alunos, utilização dos recursos pedagógicos pelos professores, mudança do paradigma da avaliação dos alunos no sentido de oportunizar a 
aprovação do maior número possível de alunos com qualidade. Ao iniciar minha jornada como gestora escolar, percebi que, às vezes, as relações humanas, interpessoais entre professores e alunos parecia uma relação de poder. $O$ professor estava sempre em posição superior ao aluno. Então, sugeri várias estratégias em que o aluno pudesse alcançar o professor e o professor alcançar o aluno. Como se um pudesse entrar no universo pessoal do outro e isso construir uma relação pessoal entre eles. Passamos a valorizar o humano na escola. $O$ aluno via o professor como um ser humano igual a ele e aprendeu a respeitar o professor como igual e não ter medo dele. Ao mesmo tempo, o professor aprendeu que o aluno o via como exemplo adulto a ser seguido. Isso foi fundamental para criar um espaço confortável de aprendizagem (Diretor O; escola estadual; 5 anos de direção escolar; estado do Amazonas - Região Norte - grifos nossos).

Existe uma figura do saber estabelecida na forma epistêmica de entender os sujeitos, ouvir e se comunicar com os diferentes agentes da escola, com objetivo de saber o que dizem, o que desejam, o que esperam da escola. Essa possibilidade de estabelecer relacionamentos em que os sujeitos podem se expor sem medo de represália é fundamental, pois se destitui o diretor centralizador e autoritário para constituir o atento e afetivamente interessado.

Fica claro que depende de todos chegar a bons resultados. Um saber que ocupa a função da direção escolar: saber, todos os dias, interagir com todos na escola. A forma como o diretor se dirige às pessoas através do diálogo, como soluciona os problemas cotidianos, repreende a ação de alguém ou comunica algo importante, define-o como sujeito que está se dispondo a ser: alguém que se preocupa com o tom de voz que utiliza na hora da comunicação, com o melhor local para tratar assuntos delicados e/ou diversos, e com cada dificuldade que surge.

O diretor "P", da Região Nordeste, revela em sua resposta um saber sobre avaliações com foco nos sentimentos dos alunos, citando a baixa autoestima e suas expectativas, além de abordar como tenta melhorar os relacionamentos na escola para aprimorar o desempenho escolar:

O colégio em que trabalho apresenta IDEB muito baixo e junto à coordenação construímos um projeto. Percebemos que este baixo índice estava muito ligado à baixa autoestima, à falta de expectativa, pela falta de oferta de emprego na cidade e à questão do pertencimento do lugar onde se vive, que a maioria dos alunos, sentia 
vergonha de dizer que era morador nato daquela cidade. Construímos um projeto para levantar a estima destes alunos e também para que valorizassem o lugar onde se vive; deu muito certo. O nosso IDEB continua baixo, mas já plantamos a sementinha e todos os anos é assim, a cada turma que entra de primeiro ano, fazemos mobilizações, falamos do projeto e o aluno sai do terceiro ano com outra visão sobre as avaliações externas e internas e conscientes do quanto elas falam muito de nós, do nosso aprendizado, da nossa história (Diretor P; escola estadual; um ano de direção escolar; Estado da Bahia - Região Nordeste - grifos nossos).

Ao abrir o diálogo, o diretor promove a gestão democrática em sua escola, um saber de quem aprendeu a se colocar no lugar do outro; alguém que sabe valorizar, que compreende não apenas a maioria, mas também as minorias. As ações declaradas nessas figuras do aprender indicam caminhos, práticas e mudanças na forma e no conteúdo da gestão escolar com vistas a uma escola democrática. A figura do saber dos diretores sobre o diálogo e gestão democrática vem se concretizando cada dia mais, com ações compartilhadas, esforços coletivos de estabelecimento de regras em conjunto etc. Um errar e acertar constante e processual, como é a democracia.

A escuta ativa pode ser planejada pelo diretor como um momento de assembleia, reunião do conselho escolar, ou com participação efetiva dos alunos, isto é, com sujeitos dispostos a ouvir, ao invés de repetir normas e exigências da escola. Isso implica em posicionar-se de forma sensível às queixas, aos pedidos, aos sonhos. Interagir é agir entre pares. O Grêmio Estudantil (colegiado de estudantes) pode organizar, principalmente, atividades e ações que os educadores não querem fazer; dando-se condições para os alunos, elas podem ser realizadas. Esse colegiado não só proporciona uma figura de saber aos alunos em ações da escola, como propicia novos pontos de vista para estudantes; é um saber de quem vê sujeitos diferentes e aprende a respeitá-los. Essa visão fortalece o encontro de vontades individuais, devidamente respeitadas, e produz vontades coletivas, esclarecidas, isto é, considera cada um no interior do coletivo.

\section{CONSIDERAÇões FINAIS}

Este artigo teve como proposta analisar a $\mathrm{RcS}$ de diretores escolares sobre avaliações nacionais e internacionais. Com o breve panorama de políticas educacionais se percebeu a padronização de indicadores e critérios presentes nos instrumentos de coleta de dados (avaliações internas e externas), cuja linguagem padrão 
universalizante e unificadora vem retirando da escola sua identidade. A crença na capacidade reguladora dos números e índices produzidos pelas avaliações é reforçada por estratégias de planejamentos e ações discutidas neste artigo.

Charlot (2013) afirma que "não há sujeito de saber e não saber senão em uma certa relação com o mundo, que vem a ser, ao mesmo tempo e por isso mesmo, uma relação com o saber" (p. 63). Dessa forma, o que diferencia uma informação de um saber é a produção de sentido que o sujeito estabelece sobre essa informação. Todas as informações e conhecimentos sobre as avaliações nacional e internacional permitem aos diretores produzir sentido ou não sobre elas. Para Charlot (2013), o sujeito produz saber, por isso não apenas tem relação com o saber, mas é a própria relação com o saber.

As formas de relação epistêmica deste saber adquirido foram identificadas por meio de três dimensões em que o diretor possui um saber-objeto de apropriar-se de tudo que já leu, ouviu e aprendeu sobre avaliação em geral; isso faz com que ele tenha uma postura racional sobre o que deveria saber a respeito dos conhecimentos específicos. Mas, além disso, existe um saber relacionado ao realizar atividades de envolvimento, ou seja, engajar-se, dar importância, estar presente em um projeto, com base em um saber de planejar ações que envolvem as avaliações que a escola enfrenta. E, por último, tem-se o saber de querer estar junto, decidir coisas em grupo, estabelecer debates ou realizar reuniões, um saber que aprende a compreender essas atividades junto com os sujeitos envolvidos com a escola.

Finalizamos com Charlot (2013), quando diz que "a educação, indissociavelmente, é a construção de si mesmo e a apropriação do mundo humano” (p. 178), um movimento articulado do que está dentro do sujeito que vai se constituindo com o que está fora. Conhecer a RcS de diretores escolares com representatividade nas regiões do Brasil possibilitou perceber diferenças no aprender; mas, considerando-se um país quase continental, espantosas também são as semelhanças.

Sem que se queira generalizar, conclui-se que o aprender a ser diretor no Brasil, ou compreender o que sabem esses educadores, está relacionado com um saber muito mais de fora do que de dentro, isto é, um saber que vem sendo constituído de reflexões sobre informações e conhecimentos de fora. Fruto de uma pedagogia tecnicista, com anos de ausência de democracia, o diretor brasileiro possui saberes com pouca perspectiva de autonomia intelectual e prática.

Mesmo com as respostas de diretores sobre seus saberes na perspectiva mais de escuta ativa e/ou gestão democrática, percebe-se que se trata de informações e de um conhecimento que "supostamente" dá resultados, e que por isso é realizado, 
antes de ser um saber realmente adquirido, que faz sentido. É quase como obrigar a escola a ser democrática, algo impossível. Um fundamento imposto que vem da pressa de se obter resultados imediatos, como as avaliações nacional e internacional, o que não proporciona tempo para absorção desse saber democrático. Um diretor escolar que recebe pouca formação inicial para sua função, com grande rotatividade em sua carreira profissional, que estabelece seus saberes ordenado pelas Secretarias de Educação, isto é, de espaços macros da educação, sem compreensão da sua escola, do seu público alvo, da sua situação, enfim do desempenho de seus alunos, é um diretor de escola que possui $\mathrm{RcS}$ conforme seu tempo, suas obrigações imediatas, sua condição precária de ser educador no Brasil.

\section{REFERÊNCIAS}

BRASIL. Ministério da Educação. Lei de Diretrizes e Bases da Educação Nacional. Brasília, 20 dez. 1996. Disponível em: http://www.planalto.gov.br/ccivil_03/LEIS/L9394.htm. Acesso em: 24 set. 2018.

BRASIL. Ministério da Educação. Programa Internacional de Avaliação de Estudantes (Pisa). 2020. Disponível em: https://www.gov.br/inep/pt-br/areas-de-atuacao/avaliacao-e-exameseducacionais/pisa. Acesso em: 15 jan. 2021.

BRASIL. Constituição da República Federativa do Brasil, de o5 de outubro de 1988. Diário Oficial [da] República Federativa do Brasil, Brasília, o5 out. 1988.

CHARLOT, Bernard. Da relação com o saber às práticas educativas. São Paulo: Editora Cortez, 2013. (Coleção Docência em formação: saberes pedagógicos).

CHARLOT, Bernard. Educação ou barbárie? Uma escolha para a sociedade contemporânea. São Paulo: Cortez, 2020.

CHIRINEA, Andréia Melanda; BRANDÃO, Carlos da Fonseca. O IDEB como política de regulação do Estado e legitimação da qualidade: em busca de significados. Ensaio: Aval. Pol. Públ. Educ., Rio de Janeiro, v. 23, n. 87, p. 461-484, jun. 2015. Disponível em: http://www.scielo.br/scielo.php?script=sci_ arttext\&pid=So104-40362015000200461\&lng=en\&nrm=iso. Acesso em: 17 jan. 2021.

NARDI, Elton Luiz; SCHNEIDER, Marilda Pasqual; RIOS, Mônica Piccione Gomes. Qualidade na educação básica: ações e estratégias dinamizadoras. Educ. Real., Porto Alegre, v. 39, n. 2, p. 359390, jun. 2014. Disponível em: http://www.scielo.br/scielo.php?script=sci_arttext\&pid=S217562362014000200003\&lng=en\&nrm=iso. Acesso em: 17 jan. 2021.

OECD. Pisa 2018 results. Are students ready to thrive in an interconnected world? PISA, OECD Publishing, Paris, 2020.

SCHNEIDER, Marilda Pasqual; NARDI, Elton Luiz. O IDEB e a construção de um modelo de accountability na educação básica brasileira. Rev. Port. de Educação, Braga, v. 27, n. 1, p. 7-28, jun. 2014. Disponível em: http://www.scielo.mec.pt/scielo.php?script=sci_arttext\&pid=So87191872014000100002\&lng=pt\&nrm=iso. Acesso em: 17 jan. 2021. 
SILVA, Isabelle. Fiorelli. O sistema nacional de avaliação: características, dispositivos legais e resultados. Estudos em Avaliação Educacional, São Paulo, v. 21, n. 47, p. 427-448, set./dez. 2010.

\section{SOBRE AS AUTORAS}

Maria Cecília Luiz. Doutora em Educação Escolar pela Unesp/Araraquara, mestre em educação pelo PPGE/UFSCar, graduada em Licenciatura em Pedagogia pela UFSCar. Professora associada do Departamento de Educação da UFSCar, credenciada no Programa de Pós-graduação em Educação da PPGE/UFSCar na linha de pesquisa: Educação, Cultura e Subjetividade. Coordenadora do GEPESC (Grupo de Estudos e Pesquisas em Educação Subjetividade e Cultura). ORCID ID: https://orcid.org/oooo-ooo1-5140-2753.

E-mail: cecilialuiz@ufscar.br.

Aline Cristina de Souza. Doutoranda em educação pelo Programa de Pósgraduação em Educação da PPGE/UFSCar, mestre em Educação Especial pelo Programa de Pós-Graduação em Educação Especial da PPGEES/UFSCar, graduada em Licenciatura em Pedagogia e Educação Especial pela UFSCar, Membro do GEPESC (Grupo de Estudos e Pesquisas em Educação Subjetividade e Cultura). Professora substituta do Instituto Federal de São Paulo - IFSP.

E-mail: alinezenaro@gmail.com.

Viviane Wellichan. Mestre em Educação pelo Programa de Pós-graduação em Educação da PPGE/UFSCar, graduada em Licenciatura em Pedagogia pela UFSCar, Membro do GEPESC (Grupo de Estudos e Pesquisas em Educação Subjetividade e Cultura).

E-mail: viviwellichan@gmail.com.

Recebido em 15 de fevereiro de 2021 e aprovado em 14 de julho de 2021. 